\title{
Role of the optic tectum and general cortex in reptilian vision ${ }^{1}$
}

\author{
WILLIAM N. HAYES AND DAVID R. HERTZLER ${ }^{2}$ \\ STATE UNIVERSITY OF NEW YORK AT BUFFALO
}

Optokinetic performance was measured in two groups of red-eared turtles; next, one group received bilateral ablation of the general cortex and the other received bilateral ablation of the optic tectum. After recovery, optokinetic performance was measured again. Cortical ablation had no effect, whereas tectal ablation brought about a deficit in responding in a 19. stripe, but not in a 4-stripe drum. These results support the traditional view that the optic tectum is a major visual center in reptiles.

The reptilian brain is of particular interest, in an evolutionary sense, because it is at this phylogenetic level that a primitive neopallium or general cortex first appears. Kappers, Huber \& Crosby (1936) discuss this primitive neopallium, but report that the optic tectum is the main visual center in the reptile. Hertzler $\&$ Hayes (1967) have recently reported that there is some cortical involvement in reptilian vision, but that this is evident only when the cortex is ablated along with the tectum. Tectal or cortical lesions alone had little effect. The lack of effect of tectal lesions is surprising, particularly if the optic tectum serves as the main visual center in reptiles. The present study was undertaken to make a more detailed evaluation of the effects of tectal lesions as opposed to cortical ones. The optokinetic measures reported in the Hertzler and Hayes study were based upon two 1 min pre-and postoperative trials, during forward and reversed rotation of the drum. Repeated testing with longer sessions should allow a more reliable estimate of the average performance of an animal. Also, testing in more than one type of optokinetic drum may help to determine the limits of any effect which is seen. (Ter Braak, 1936; Smith, 1937). Subjects

Twelve red-eared turtles, pseudemys scripta, carapace length 6 to 10 in. served as the Ss in the experiment.

\section{Apparatus}

Cylinders of white translucent plastic, 12 in.high and 12 in. across, were mounted on the shafts of two variable speed electric motors. One cylinder had alternating black and white stripes 1 in. wide, with a total of 19 black stripes. The other cylinder had only four black stripes placed $90^{\circ}$ apart within the cylinder. The cylinders were always rotated at a calibrated $21.5 \mathrm{rpm}$ (angular velocity $128 \% \mathrm{sec}$ ).

\section{Procedure}

Ss were placed on plastic disks and restrained with rubber straps. They were then suspended within the lighted cylinders in such a position that they could be easily observed by $\mathrm{E}$. $\mathrm{E}$ observed the animal through a half-silvered mirror, and pressed a switch every time an optokinetic response (OKR) was observed. Each time the switch was closed, this registered on a counter. Five such counters were stepped at $1 \mathrm{~min}$ intervals, while a sixth registered the total number of responses for the $5 \mathrm{~min}$ period.

The animals were run in one drum in the morning and the other in the afternoon, with atleast $3 \mathrm{~h}$ between sessions. The order in which the drums were given was counterbalanced. This was done for three days, and the order was reversed from day to day. On the fourth day, the animals were operated upon. The operative procedures have been described previously (Hertzler \& Hayes, 1967). Two types of ablation were performed: The optic tectum was removed in six animals, and the general cortex was removed in the remaining six. Assignment to the cortical or tectal condition was random.

Postoperative testing began on the following day and continued for three days. Upon completion of this testing, the animals were sacrificed. The brains were removed and placed in $10 \%$ formalin for atleast one week, usually two. After embedding in celloidin, sections were cut at $40 \mu$. Every 10 th and 11th section was saved and stained alternately with Nissl and Weil. Tracings of the lesions were made using a microprojector. Examples are shown in Fig. 1. The tectal lesions were not always complete, but were sizeable in every case. The cortical lesions sometimes impinged upon the adjacent piriform

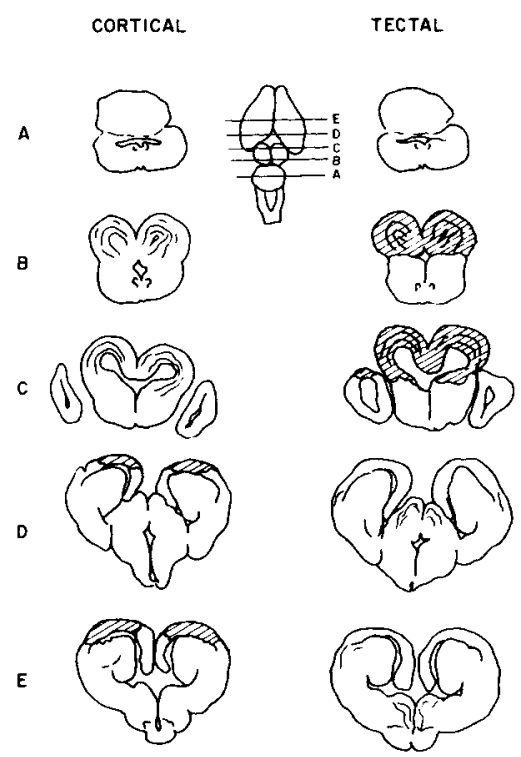

Fig. 1. Representative sections from each group. 




Fig. 2. Preoperative performance in the two drums.

cortex or hippocampus, or rarely upon the underlying striatum.

\section{Results}

Preoperative comparisons between the two groups of animals showed that the total number of responses of the two groups did not differ significantly, and that the responses for each of the $5 \mathrm{~min}$, totaled over the three days, did not differ significantly. Figure 2 shows the preoperative performance of the two groups.

The median dally preoperative score was taken as most representative of the average performance of each animal. The differences between the scores on the postoperative test days and this median were computed for each of the drums. Mann-Whitney $U$ tests were used to compare the groups with each other and Wilcoxon tests for matched pairs or Friedman analysis of variance by ranks was used for pre- versus postoperative comparisons.

An examination of the total scores on the two drums showed that performance in the 4-stripe drum was not significantly altered by either cortical or tectal lesions, but that the 19-stripe drum scores for the tectal animals were significantly lower after the operation. The cortical animals were unaffected by their surgery, regardless of the drum used.

Comparison of the postoperative performance in the 19-stripe drum showed that tectal performance was significantly lower than cortical on Day $1(p=.047)$, almost significant on Day $2(p=.066)$, and significantly different again on Day $3(p=.032)$. Figure 3 illustrates these results.

Ratios of the total postoperative scores over the total preoperative scores for each of the minutes were calculated. If a differential effect of tectal lesions on the various minutes was present, these ratios should change

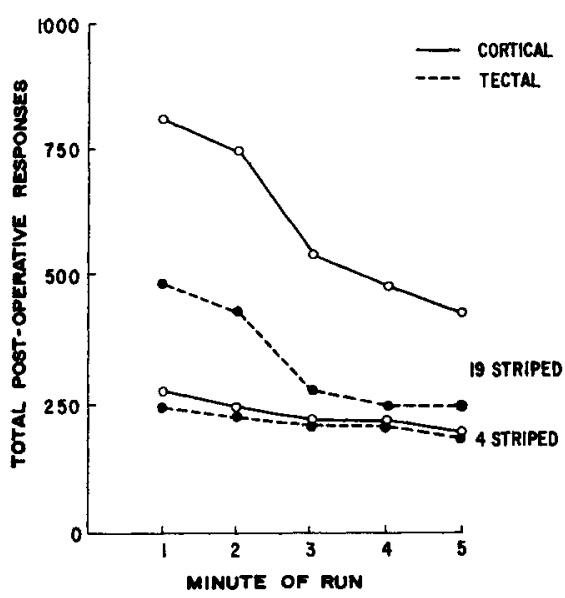

Fig. 3. Postoperative performance in the two drums.

in some regular way. A Friedman analysis of variance by ranks showed that no such change was present $(.10<\mathrm{p}<.20)$.

\section{Discussion}

It appears that there is an effect of tectal lesions upon the optokinetic response, but that it can only be seen under special conditions. Relatively long term runs in the drum are required, and repeated measures also are helpful. Further, only when the number of stripes is high will such an effect be present. It is interesting to note that lesions of the striate cortex in mammals bring about a reduction or elimination of response to single stripes with no deficit in response to multiple stripes (Smith, 1937; Ter Braak, 1936). Cortical lesions, on the other hand, have no effect under any of the conditions of these experiments. Hertzler and Hayes have previously shown, however, that cortical damage will have some effect when combined with tectal damage.

It seems that the tectum can safely be considered the primary or dominant visual center in reptiles, but the cortex has a functional role also.

\section{References}

HERTZLER, D. R., \& HAYES, W. N., Cortical and Tectal function in visually guided behavior of turtles. J. comp. physiol. Psychol., 1967, 63, 444-447.

KAPPERS, C. U., HUBER, G. C., \& CROSBY, E. C. The Comparative Anatomy of the Nervous System of Vertebrates. New York: Hafner, 1936.

SMITH, K. U. The relation between visual acuity and the optic projection centers of the brain. Science, 1937, 86, 564-565.

TER BRAAK, J. W. G. Untersuchungen euber optokinetischen Nystagmus Arch. neerl. de Physiol., 1936, 21, 309-376.

Notes

1. This research was supported by research Grant NB-05-001 from the National Institutes of Health.

2. Present address: Department of Psychology, Princeton University, Princeton, N. J. 